\title{
Exposure to polycyclic aromatic hydrocarbons in coal liquefaction workers: impact of a workwear policy on excretion of urinary 1-hydroxypyrene
}

\author{
R Quinlan, G Kowalczyk, K Gardiner, I Calvert
}

\begin{abstract}
Objective-This study was undertaken to assess whether contaminated personal clothing worn beneath a coverall (normal workwear) is a source of potentially significant dermal exposure to polycyclic aromatic hydrocarbons (PAHs) in coal liquefaction workers.

Methods-An intervention study was conducted over a two week period involving 10 workers that reflected the range of activities performed at the factory. A cross over design was used to examine the influence of normal workwear (personal clothing worn beneath a coverall) and intervention workwear (new coverall, shirt, trousers, underwear, socks, and boots) upon excretion of urinary 1hydroxypyrene (1-OHP) and skin pad deposition of pyrene.
\end{abstract}

Results-The impact of intervention was noted in three ways:

(1) A notable reduction (55\%) in the mass of 1-OHP excreted on the first day of the intervention phase was found. The median reduction in mass excreted $(22.7$ nmol) was significant from zero at the $5 \%$ level; (95\% confidence interval $(95 \% \mathrm{CI})$ 9.5-40.8 nmol).

(2) A notable reduction (82\%) in skin pad deposition of pyrene on the first day of the intervention phase was found. The median reduction of $13.20 \mathrm{ng} \cdot \mathrm{cm}^{-2}$ was significant from zero at the $5 \%$ level; (95\% CI 7.3-26.4 ng. $\mathrm{cm}^{-2}$ ).

(3) About a $50 \%$ reduction in 1-OHP concentration over the working week occurred during the intervention phase; an increase of $2.07 \mu \mathrm{mol} / \mathrm{mol}$ creatinine was found from the start to the end of the work period during the intervention phase compared with an increase of 4.06 $\mu \mathrm{mol} / \mathrm{mol}$ creatinine during the normal phase. This reduction was not significant at the $5 \%$ level.

Conclusion-The results indicate that on the first day of the working week investigated, significant reductions in absorbtion (as measured by excretion of urinary 1-OHP) and deposition of PAHs (as measured by skin pad deposition of pyrene) can be effected by improvements in workwear policy. The impact of the improved workwear regimen was also detected by reduction in spot urinary 1-OHP concentrations, although this effect was less pronounced. One implication of the findings is that exposure to
PAHs may arise from workers' own contaminated personal clothing. As a consequence of this study an improved workwear policy has been implemented at the factory.

\section{(Occup Environ Med 1995;52:600-605)}

Keywords: polycyclic aromatic hydocarbons, 1hydroxypyrene, workwear

Coal liquefaction involves the transformation of coal into hydrocarbon fractions that can be used as transport fuels. The process has been previously described ${ }^{1}$ and only a brief summary is included here. In the extraction stage coal is digested in anthracene oil, which possesses hydrogen donation properties. About $85 \%$ by weight of coal passes into solution. The digest is filtered to remove undissolved coal and mineral matter, and clean coal solution is catalytically hydrocracked in a trickle bed reactor. The main products are naphtha (initial boiling point up to $170^{\circ} \mathrm{C}$ ), middistillates $\left(170^{\circ} \mathrm{C}-450^{\circ} \mathrm{C}\right)$, and a small amount of heavy products $\left(>450^{\circ} \mathrm{C}\right)$. The naphtha and mid-distillates need to be chemically refined to make quality petrol and diesel fuels. The pilot plant converts 2.5 tonnes of coal a day into light distillates $(35 \%-47 \%$ distillate/tonne of coal received).

The process stream consists of complex mixtures that are mainly polycyclic aromatic hydrocarbons (PAHs) of which some are known carcinogens. ${ }^{2}$ Previous studies at the coal liquefaction factory have concluded that: (1) Measurement of 1-hydroxypyrene (1-OHP) in urine specimens taken at the end of the work shift is a valid measure of total exposure to and absorption of PAHs in coal liquefaction workers. ${ }^{1}$

(2) Group median 1-OHP concentrations can be used as an effective indicator of hygiene performance at the factory. ${ }^{3}$

(3) The potential for exposure to the process stream materials occurs during both routine and non-routine tasks and is primarily dermal. ${ }^{3}$

Control of health risks at the factory is effected by a detailed occupational health programme that involves routine medical surveillance, annual biological and atmospheric monitoring, and adherence to good occupational hygiene practices. As well as showering facilities and skin luminoscope examinations, hygiene practices at the factory rely in part on provision of protective clothing to minimise any possibility of dermal exposure to coal 
liquefaction materials. Workers are issued with protective coveralls, protective gloves, and boots; beneath these items workers wear their own personal clothing and underwear.

Workwear permeability studies (Walton, personal communication) have shown that Arco Coroguard TP Coveralls (Proban-100\% cotton drill; 305 g. $\mathrm{m}^{2}$ ) provide the best protection against penetration by process liquids. Each worker at the factory is provided with two coveralls for routine everyday use. Although these items provided by the factory are laundered regularly, responsibility for laundering personal clothing worn beneath coveralls is left to each worker.

Previous studies of occupational hygiene practices at the factory have highlighted the potential for dermal exposure and absorption of PAHs, and measures have been taken through improved working practices to increase worker awareness of skin contamination. These activities have resulted in successive annual reductions in excretion of 1-OHP at the factory. This provides a quantitative measure of improvements in occupational hygiene. Nevertheless, despite these improvements, relatively high concentrations of 1 OHP are still being detected in workers and further action to reduce these exposures is therefore still warranted.

Van Rooij and co-workers have shown that a substantial amount of dermal contamination by PAHs can arise on areas of skin covered by workwear, which suggests that when contaminated this may be an important source of dermal exposure. ${ }^{45}$ Our observations of working practices have indicated that contaminated workwear may also be a potential source of exposure to PAHs in coal liquefaction workers.

To determine whether the workwear practices (personal clothing worn beneath a coverall) in the liquefaction factory could contribute to total exposure of PAHs, the impact of an improved workwear regimen (new coverall, shirt, trousers, underwear, socks, and boots) was assessed principally by monitoring changes in excretion of 1-OHP. Should the normal workwear be a source of exposure to PAHs, then reductions in 1-OHP would be anticipated after improvements in the workwear regimen. Also skin pads were used in this study to obtain evidence of direct deposition on the skin at sites covered by workwear.

Several methods are available for measuring dermal deposition; garment samplers, surrogate skin samples, fluorescent tracer techniques, skin washing, tape stripping, and surface wipes. The appropriateness and limitations of these techniques have been recently reviewed by Fenske. ${ }^{6}$ We chose to use skin pads as a surrogate skin sampler, as these had been successfully applied in previous studies of dermal exposure to PAHs. ${ }^{458}$ Although skin pads have been used as measures of total dermal deposition of substances and possibly also of the quantity of dermally absorbed material, our application of the technique was of a more limited nature and was aimed at finding whether a difference in pad deposition was obvious between the two workwear phases. The skin pads were located on sites covered by protective clothing and were designed to detect any transfer of PAHs that may arise either through the protective clothing or from PAHs already deposited on the clothing. Two skin pads per person were used on the first day back at work when the maximum benefit of the intervention strategy was likely.

\section{Materials and methods \\ DESIGN AND SAMPLE SIZE}

An intervention study ${ }^{9}$ with a crossover design $^{10}$ was used in which the differences in excretion of 1-OHP and skin pad deposition of pyrene in a group of exposed workers were compared during a normal workwear phase and an intervention workwear phase (table 1). The advantages of the crossover design were threefold; firstly the design allowed more observations for the given sample size, secondly every worker acted as his own control thus eliminating variations between workers, and finally the design aimed to reduce the potential bias from variability in exposure over two consecutive work periods (weeks).

At the liquefaction factory workers who may be exposed to the process material are engineers, responsible for monitoring plant equipment and sampling process streams, and maintenance workers who are required to attend routine maintenance procedures and unexpected occurrences, for example process stream blockages. The study took place during two consecutive working weeks. For the engineers each working week consisted of four 12 hour shifts and consecutive weeks were separated by four days off. For the maintenance staff each working week consisted of five eight hour shifts and consecutive weeks were separated by two days off.

There was a total population of 35 workers available for investigation. Ten workers (five engineers and five technicians) were selected as follows; of the 20 engineers on site (four shift teams, each of five workers) one shift team (E2, E9, E10, E11, and E12) was randomly selected and consisted entirely of non-smoking Caucasian men aged 36 to 53

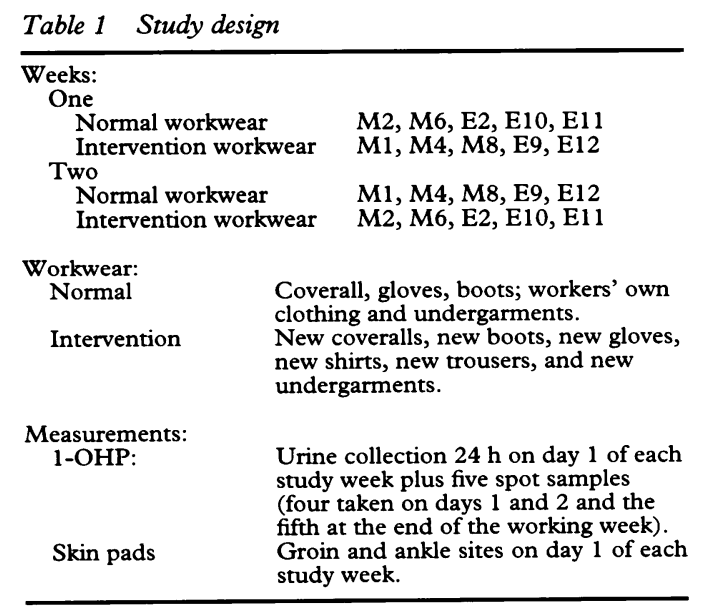


years (mean 43.6). Their job experience at the factory was between three and five years (mean 3.8) and all were clinically in good health. Of the 15 technicians on site five were selected to give a stratified sample that reflected the range of activities performed by maintenance workers and consisted of three mechanical technicians (M4, M6, and M8), one instrument technician (M2), and one manual technician (M1). All were Caucasian men aged 31 to 52 years (mean 44.6 years) with between one and five years (mean 2.4 ) job experience at the factory. All were clinically in good health. Three of them were smokers, but smoking was strictly prohibited at the workplace. The 10 workers were randomly assigned to one of two study groups; intervention workwear phase followed by normal workwear phase for workers $\mathrm{M1}, \mathrm{M} 4$, M8, E9, and E12, and normal workwear phase followed by intervention workwear phase for workers M2, M6, E2, E10, and E11. An information sheet was distributed to the participants to brief them of all the relevant facets of the study. A self administered diary card was used for each week and included information on age, smoking habits, diet, medication, and nature of workwear. Informed consent was obtained and each worker had the right to withdraw from the study at any time. After analysis and interpretation of the data, workers were informed of their own individual results and the employer was provided with group data.

\section{STRATEGY OF URINARY 1-OHP SAMPLING}

Six urine samples were taken from each person during each of the two consecutive working weeks. These were one 24 hour urine collection on the first day of each working week, four spot samples during the first 24 hours after the start of each working week (start of shift on day 1, end of shift on day 1 , midway between shifts on days 1 and 2 , and start of shift on day 2) and a further spot sample at the end of each working week. A total of 120 samples were taken for analysis.

The impact of intervention workwear was assessed by changes in: (a) the mass of 1-OHP excreted in the first 24 hours of each sampling period-that is, on return to work after a break - and by $(b)$ the changes between concentrations of 1-OHP at the start and the end of the working week. Taking additional spot samples - that is, at the end of the first shift, midway between shifts, and at the start of the second shift-allowed for a comparison to be made between the mass of excreted 1OHP derived from a 24 hour urine collection, with the value obtained by calculating area under the excretion rate/time curves.

STRATEGY FOR SKIN PAD SAMPLING

As the impact of intervention workwear was likely to be most significant on the first day of each working week (the potential benefits of new clothing would be likely to be diminished by contamination with process material on subsequent days) skin pads were worn only on these days. Exposure pads consisted of a soft polypropylene adsorbing material surrounded by self adhesive tape for fixation to the skin.? Each worker had two exposure pads to monitor dermal contamination during the entire work shift at body sites most likely to be contaminated by penetration and permeation through clothing. The groin (junctional region between thigh and abdomen) and the forefoot on the dominant side were used.

\section{ANALYSES}

Urine samples

After collection, urine samples were stored at $-20^{\circ} \mathrm{C}$. All samples were coded and the person who undertook the analysis was blind to the sample sources. Urinary 1-OHP concentrations were measured by high performance liquid chromatography (HPLC). The method was based on those described by Jongeneelen $e t$ $a l,{ }^{11}$ Tolos et $a l,{ }^{12}$ and Gardiner et $a l^{13}$ but incorporated modifications as previously reported in detail. ${ }^{1}$

\section{Exposure pads}

After removal exposure pads were packed in aluminium foil and kept in the dark at $4^{\circ} \mathrm{C}$ until subsequent analysis for pyrene and benz(a)pyrene. The method involved extraction by dichloromethane followed by high performance liquid chromatographic separation and fluorescence detection.

\section{Treatment of data}

Differences between the effects of normal workwear and intervention workwear on excretion of 1-OHP and skin pad deposition of pyrene were examined. Non-parametric statistical methods (Wilcoxon signed rank test), with Minitab software, were used as the number of subjects was small and the observations were not expected to be normally distributed.

\section{Results}

The study investigated two workwear phases, (normal workwear $v$ intervention workwear), two consecutive work periods (each period containing a mixture of normal and intervention workwear) and two exposure groups (one in the first instance wearing normal workwear followed by intervention workwear, and the other wearing intervention workwear followed by normal workwear).

Only the first comparison, normal workwear phase $v$ intervention workwear phase, showed a significant difference in excretion of 1-OHP and skin pad deposition of pyrene. No significant difference in excretion of 1-OHP or skin pad deposition of pyrene was found when the two consecutive working weeks or the two exposure groups were compared.

Tables 2 and 3 relate to information obtained on day 1 of each working week. Table 2 shows the difference between the effects of normal workwear and intervention workwear on mass of 1-OHP excreted over one day as determined from a complete 24 hour urine collection. A notable reduction (55\%) was achieved during the intervention 
Table 2 Mass of 1-OHP excreted (nmol; $24 \mathrm{~h}$ urine collection) on day 1 of each working week (normal $v$ intervention workwear) for engineers and maintenance workers $(n=10)$

\begin{tabular}{|c|c|c|c|}
\hline Worker number & $\begin{array}{l}\text { Normal } \\
\text { workwear day } 1\end{array}$ & $\begin{array}{l}\text { Intervention } \\
\text { workwear day } 1\end{array}$ & $\begin{array}{l}\text { Change in mass } \\
\text { excreted }\end{array}$ \\
\hline $\begin{array}{l}\text { E2 } \\
\text { E9 } \\
\text { E10 } \\
\text { E11 } \\
\text { E12 } \\
\text { M1 } \\
\text { M2 } \\
\text { M4 } \\
\text { M6 } \\
\text { M8 } \\
\text { Median }(n=10)\end{array}$ & $\begin{array}{r}37 \cdot 92 \\
125 \cdot 78 \\
42 \cdot 41 \\
43 \cdot 64 \\
8 \cdot 43 \\
69 \cdot 12 \\
65 \cdot 70 \\
69 \cdot 31 \\
67 \cdot 77 \\
67 \cdot 55 \\
66 \cdot 62\end{array}$ & $\begin{array}{l}12 \cdot 35 \\
60 \cdot 48 \\
22 \cdot 57 \\
14 \cdot 98 \\
15 \cdot 76 \\
34 \cdot 84 \\
24 \cdot 78 \\
52 \cdot 73 \\
51 \cdot 57 \\
65 \cdot 14 \\
29 \cdot 81\end{array}$ & $\begin{array}{l}-25 \cdot 57 \\
-65 \cdot 30 \\
-19 \cdot 84 \\
-28 \cdot 66 \\
+7 \cdot 33 \\
-34 \cdot 28 \\
-40 \cdot 92 \\
-16 \cdot 58 \\
-16 \cdot 20 \\
-2 \cdot 41 \\
-22 \cdot 70\end{array}$ \\
\hline
\end{tabular}

phase; normal workwear phase median $66 \cdot 62$ (range 8.43-125.78) nmol $v$ intervention workwear phase median 29.81 (range $12 \cdot 35-65 \cdot 14) \mathrm{nmol}$. The median reduction in mass excreted $(22.7 \mathrm{nmol})$ was significantly different from zero at the 5\% level (95\% CI 9.5-40.8 nmol). Only one person (E12) did not show a decrease in mass of 1-OHP excreted during the intervention strategy, but this may be due to an abnormally low result (median 8.43 $v 66.2 \mathrm{nmol}$ ) recorded during the normal workwear period. Review of the diary cards of work activities undertaken did not provide an explanation for this finding: the low urine collection over 24 hours $(0.681)$ may have been a factor, but the total creatinine output of $7.8 \mathrm{mmol}$ over 24 hours, although low was not dissimilar from findings during the intervention phase $(10 \mathrm{mmol}$ excreted in 2.221 collected). This 24 hour excretion data for this person is also inconsistent with the skin pad deposition data (see next paragraph and table 3 ) and remains unexplained, although a discrepancy in the 24 hour urine collections is a possible explanation as is excretion of 1-OHP arising from dietary and environmental sources during the intervention period that were not adequately recorded in the diary card.

The effects of the intervention phase upon skin pad deposition (table 3) supports the findings already discussed. A notable reduction in deposition ( $82 \%$ ) was achieved with intervention; normal workwear median 16 (range 6.90-44.50) ng. $\mathrm{cm}^{-2} v$ intervention workwear median 2.80 (range $2 \cdot 80-7 \cdot 05$ ) ng. $\mathrm{cm}^{-2}$. The median reduction, 13.20 ng. $\mathrm{cm}^{-2}$ was significant at the $5 \%$ level $(95 \%$ CI $7 \cdot 3-26.4 \mathrm{ng} . \mathrm{cm}^{-2}$ ). The skin pads were also analysed for benzo(a)pyrene but all results were below the limit of detection $(0.05$ ng). Considering that the pyrene to benzo(a)pyrene ratio is greater than 450 in both airborne and liquid phases $^{3}$ a much higher (about 10-fold) pyrene deposition, in the order of $150 \mathrm{ng} . \mathrm{cm}^{-2}$ per pad would have been required for benzo(a)pyrene to reach the level of detection.

The impact of intervention over the whole working week was also assessed (table 4). A reduction in the concentration of 1-OHP at the end of the working week was found; intervention $v$ normal workwear median $5.73 v$ $7.46 \mu \mathrm{mol} / \mathrm{mol}$ creatinine. Also, the increase in concentration of 1-OHP was on average $50 \%$ lower during intervention $2.07 v 4.06$ $\mu \mathrm{mol} / \mathrm{mol}$ creatinine. Neither result, however, achieved significance at the $5 \%$ level.

The results were also analysed after excluding values for workers M4 and M6 as they worked through the weekend before the normal workwear phase and therefore their samples from the start of the work period could not be regarded as true baselines. The value at the end of the work period for E2 during the normal workwear phase was also excluded on the basis of a low creatinine value $(<4 \mathrm{mmol} / \mathrm{l}),{ }^{8}$ which might possibly have resulted in a high 1-OHP reading. With these exclusions there was still a substantial impact of intervention upon excretion of 1-OHP although significance was not reached.

\section{Discussion}

A large and significant effect was seen on the first day of intervention, as measured by 24 hour mass of 1-OHP and skin pad deposition of pyrene (tables 2 and 3). The magnitude of this effect, however, was not maintained at the end of the study period where the impact upon the concentrations of 1-OHP at the end of the working week was smaller and not significant (table 4). A possible explanation might be that as intervention clothing becomes contaminated during the working

Table 3 Deposition of pyrene (ng.cm-2) on skin pads on day 1 of each working week (normal v intervention workwear) for engineers and maintenance workers $(n=10)$

\begin{tabular}{|c|c|c|c|c|c|c|c|}
\hline \multirow[b]{3}{*}{ Worker number } & \multicolumn{3}{|c|}{ Normal workwear day 1} & \multicolumn{3}{|c|}{ Intervention workwear day 1} & \multirow{3}{*}{$\begin{array}{l}\text { Changes } \\
\text { in pad } \\
\text { deposition }\end{array}$} \\
\hline & \multicolumn{2}{|c|}{ Skin pad sites } & \multirow{2}{*}{$\begin{array}{l}\text { Mean } \\
\text { value }\end{array}$} & \multicolumn{2}{|c|}{ Skin pad sites } & \multirow{2}{*}{$\begin{array}{l}\text { Mean } \\
\text { value }\end{array}$} & \\
\hline & Foot & Groin & & Foot & Groin & & \\
\hline $\begin{array}{l}\text { E2 } \\
\text { E9 } \\
\text { E10 } \\
\text { E11 } \\
\text { E12 } \\
\text { M1 } \\
\text { M2 } \\
\text { M4 } \\
\text { M6 } \\
\text { M8 } \\
\text { Median }(n=10)\end{array}$ & $\begin{array}{l}24 \cdot 00 \\
41 \cdot 60 \\
14 \cdot 10 \\
15 \cdot 10 \\
\text { ND } \\
\text { ND } \\
7 \cdot 50 \\
10 \cdot 40 \\
\text { ND } \\
11 \cdot 30\end{array}$ & $\begin{array}{l}14 \cdot 10 \\
47 \cdot 70 \\
14 \cdot 90 \\
21 \cdot 00 \\
22 \cdot 40 \\
16 \cdot 80 \\
29 \cdot 80 \\
78 \cdot 30 \\
11 \cdot 30 \\
16 \cdot 80\end{array}$ & $\begin{array}{r}17 \cdot 50 \\
44 \cdot 50 \\
14 \cdot 50 \\
18 \cdot 05 \\
12 \cdot 60 \\
9 \cdot 80 \\
18 \cdot 65 \\
44 \cdot 35 \\
6 \cdot 90 \\
9 \cdot 05 \\
16 \cdot 00\end{array}$ & $\begin{array}{l}\text { ND } \\
11 \cdot 30 \\
\text { ND } \\
\text { ND } \\
\text { ND } \\
\text { ND } \\
\text { ND } \\
\text { ND } \\
\text { ND } \\
\text { ND }\end{array}$ & $\begin{array}{l}\text { ND } \\
\text { ND } \\
\text { ND } \\
\text { ND } \\
\text { ND } \\
\text { ND } \\
\text { ND } \\
\text { ND } \\
\text { ND } \\
9 \cdot 30\end{array}$ & $\begin{array}{l}2 \cdot 80 \\
7 \cdot 05 \\
2 \cdot 80 \\
2 \cdot 80 \\
2 \cdot 80 \\
2 \cdot 80 \\
2 \cdot 80 \\
2 \cdot 80 \\
2 \cdot 80 \\
6 \cdot 05 \\
2 \cdot 80\end{array}$ & $\begin{array}{r}-14 \cdot 70 \\
-37 \cdot 00 \\
-11 \cdot 70 \\
-15 \cdot 25 \\
-9 \cdot 80 \\
-7 \cdot 00 \\
-15 \cdot 85 \\
-41 \cdot 55 \\
-\quad 4 \cdot 10 \\
-3 \cdot 00 \\
-13 \cdot 20\end{array}$ \\
\hline
\end{tabular}

$\mathrm{ND}=$ not detectable $\left(<5.6 \mathrm{ng} \cdot \mathrm{cm}^{-2}\right)$, to show average pad concentrations, $50 \%$ of the detection limit $=2.8 \mathrm{ng} \cdot \mathrm{cm}^{-2}$ was used in calculations. 
Table 4 1-OHP results ( $\mu \mathrm{mol} / \mathrm{mol}$ creatinine) for normal $v$ intervention workwear for engineers over a four day working week $(96 h)$ and maintenance workers over a five day working week $(104 h)(n=10)$

\begin{tabular}{|c|c|c|c|c|c|c|}
\hline \multirow[b]{2}{*}{ Worker number } & \multicolumn{3}{|c|}{ Normal workwear } & \multicolumn{3}{|c|}{ Intervention workwear } \\
\hline & $\begin{array}{l}\text { Start of } \\
\text { week }\end{array}$ & $\begin{array}{l}\text { End of } \\
\text { week }\end{array}$ & $\begin{array}{l}\text { Change over } \\
\text { working week }\end{array}$ & $\begin{array}{l}\text { Start of } \\
\text { week }\end{array}$ & $\begin{array}{l}\text { End of } \\
\text { week }\end{array}$ & $\begin{array}{l}\text { Change over } \\
\text { working week }\end{array}$ \\
\hline $\begin{array}{l}\text { E2 } \\
\text { E9 } \\
\text { E10 } \\
\text { E11 } \\
\text { E12 } \\
\text { M1 } \\
\text { M2 } \\
\text { M4 } \\
\text { M6 } \\
\text { M8 } \\
\text { Median }(n=10)\end{array}$ & $\begin{array}{r}0 \cdot 74 \\
5 \cdot 08 \\
1 \cdot 40 \\
0 \cdot 83 \\
0 \cdot 73 \\
2 \cdot 19 \\
3 \cdot 30 \\
9 \cdot 59 \\
15 \cdot 43 \\
3 \cdot 25 \\
2 \cdot 72\end{array}$ & $\begin{array}{r}48 \cdot 47 \\
36 \cdot 33 \\
3 \cdot 83 \\
7 \cdot 96 \\
2 \cdot 79 \\
4 \cdot 33 \\
8 \cdot 85 \\
5 \cdot 48 \\
8 \cdot 07 \\
7 \cdot 04 \\
7 \cdot 46\end{array}$ & $\begin{array}{l}+47 \cdot 73 \\
+31 \cdot 25 \\
+\quad 2 \cdot 43 \\
+7 \cdot 13 \\
+2 \cdot 06 \\
+2 \cdot 14 \\
+5 \cdot 55 \\
+4 \cdot 11 \\
-7 \cdot 36 \\
+3 \cdot 79 \\
+4 \cdot 62\end{array}$ & $\begin{array}{l}0 \cdot 38 \\
3 \cdot 62 \\
1 \cdot 15 \\
0 \cdot 37 \\
1 \cdot 04 \\
1.94 \\
2 \cdot 78 \\
5.99 \\
3.79 \\
4.57 \\
2 \cdot 36\end{array}$ & $\begin{array}{l}8 \cdot 33 \\
8 \cdot 32 \\
7 \cdot 33 \\
4 \cdot 48 \\
4 \cdot 41 \\
3 \cdot 22 \\
3 \cdot 88 \\
4 \cdot 81 \\
6 \cdot 65 \\
7 \cdot 65 \\
5 \cdot 73\end{array}$ & $\begin{array}{l}+7 \cdot 95 \\
+4 \cdot 70 \\
+6 \cdot 18 \\
+4 \cdot 11 \\
+3 \cdot 10 \\
+1 \cdot 28 \\
+1 \cdot 11 \\
-1 \cdot 18 \\
+2 \cdot 86 \\
+3.08 \\
+2 \cdot 07\end{array}$ \\
\hline
\end{tabular}

week, the benefit of the new clothing may be diminished over time; maximum effect of intervention would therefore be anticipated to arise on the first day.

On review of the data for the first day of each study phase, there was evidence of some association between mass of 1-OHP excreted and the deposition of pyrene on the skin pads during both the intervention and normal workwear phases (figure). The lack of a correlation is not unexpected, for although mass of $1-O H P$ is a reflection of total dose of pyrene absorbed, the deposition of pyrene on two selectively placed skin pads is not of itself a direct index of deposition of pyrene over the whole body, nor more importantly of whole body uptake of pyrene. The gradient, however, was steeper for the normal workwear phase, which may suggest that deposition on the skin contributes more to total exposure during the normal workwear phase than the intervention workwear phase. This is further reinforced by the finding that the highest pad contamination was found during the normal workwear phase and corresponded with the highest mass of 1-OHP excreted and the concentration at the end of the working week (engineer E9; normal working period, tables

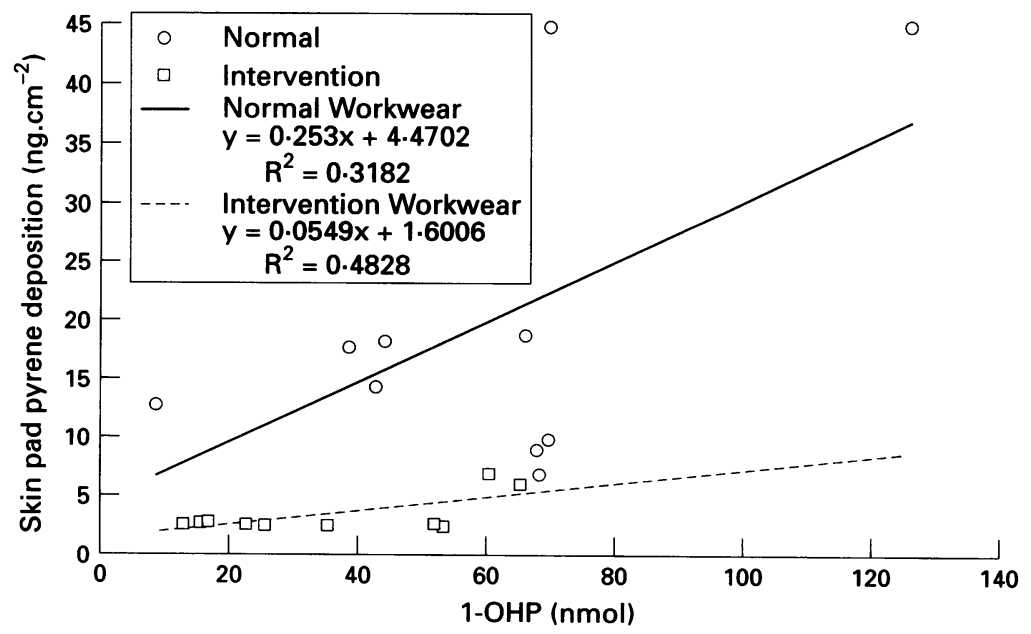

Relation between mass of 1-OHP excreted and skin pad deposition of pyrene for normal and intervention workwear.
2, 3, and 4). This implies that intervention prevented deposition on the skin and that the excretion of 1-OHP for the intervention group may be largely attributable to inhalation.

The mass of 1-OHP excreted during the normal workwear period was consistent with previously estimated values at the factory ${ }^{3}$ and was similar in magnitude to results in other studies. ${ }^{45781415}$

A comparison was made between the mass of 1-OHP excreted from 24 hour urine collections and calculation from area under excretion rate/time curves derived from data of 1-OHP concentration as previously reported. ${ }^{3}$ In summary this involved the calculation of excretion rates of 1-OHP of individual people $(\mu \mathrm{mol} / \mathrm{h})$ and subsequent determination of the area under excretion rate/time curves to estimate total mass excreted over a given timethat is, in 24 hours. With only four data points; start of the working week, end of the first shift, midway between shifts, and at the start of the second shift, area under the curve calculations tended to overestimate the mass excreted by about threefold. This finding shows the limitation inherent in attempting to use a few spot urine results to estimate mass excreted. From our findings many more than four data points would be needed to convert spot sample data into a reasonable estimate of total mass excreted.

There has been much criticism of the use of deposition pads as quantitative measures of dermal contamination, ${ }^{6}$ but the use in this study was of a much more limited nature, because the magnitude of deposition was used as a comparative indicator of deposition over the phases of the study under investigation. No prediction of the total amount of dermally deposited material, nor of the material absorbed by the skin, was attempted from our deposition data. We consider that the use of skin deposition pads in this limited way is entirely justified, and can provide an important source of information.

The study further shows the usefulness of urinary 1-OHP in securing improvements in workplace control and protection for groups of workers who may be exposed to PAHs. Although this study investigated the effect of changes in workwear policy upon the excretion profile of 1-OHP, the biological 
monitoring technique lends itself to the assessment of other controls that may influence exposure in the workplace-for example, improved ventilation, washing facilities, or changes to working practices, such as shift patterns. Also, a crossover design allows workers to act as their own controls and removes many of the confounding factors in such investigations.

Successive studies ${ }^{13}$ at the factory have shown small reductions in median urinary concentrations of 1-OHP at the end of the work period as working practices and hygiene awareness have improved. The effect of the intervention workwear policy upon this value has so far provided the highest impact, and has reduced the previously lowest median value of $7 \mu \mathrm{mol} / \mathrm{mol}$ creatinine to $5 \cdot 46$. This is a clear indication that a further improvement in hygiene at the factory can be achieved by changes in workwear policy. Ideally the workwear policy should be daily provision of clean clothing and frequent chemical cleaning of this clothing would be desirable; however, this ideal was precluded on cost grounds. As a result, the following recommendations were made to management; no personal clothing should be worn and workers should be provided with two sets of workwear, including underclothes. During normal working activities, workwear should be changed at least weekly. Outer clothing should preferably be laundered by a dry cleaning method, as normal washing procedures are not effective in removing contamination of PAHs (Van Rooij, personal communication). Additional workwear should be available for workers accidentally contaminated by process material.

It is anticipated that the impact of these changes will further improve the occupational hygiene practices at the factory and will reduce even further potential exposure to and absorption of process material.

Mr K Hale, Regional Laboratory for Toxicology, City Hospital NHS Trust, Birmingham, and Drs F Jongeneelen and J Van Rooij, IndusTox, University Business Park, Nijmegen, Netherlands are gratefully acknowledged for carrying out analyses of urinary 1-hydroxypyrene and skin pad pyrene and benz(a)pyrene, respectively.

1 Quinlan R, Kowalczyk G, Gardiner K, Hale K, Walton S, Calvert I. Urinary 1-hydroxypyrene: a biomarker for polycyclic aromatic hydrocarbon exposure in coal liquefaction workers. Occup Med 1995;45:63-8.

2 International Agency for Research on Cancer. Monographs on the evaluation of the carcinogenic risk of chemicals to
humans. Vol 35. Polynuclear aromatic compounds. Part 1. humans. Vol 35. Polynuclear aromatic compounds. Part 1. IARC, 1983 .

3 Quinlan R, Kowalczyk G, Gardiner K, Calvert I, Hale K, Walton S. Polycyclic aromatic hydrocarbon exposure in coal liquefaction workers. The value of urinary 1-hydroxypyrene excretion in the development of occupational hygiene control strategies. Ann Occup Hyg 1995;39:329-46.

4 Van Rooij JGM, Van Lieshout EMA, Bodelier-Bade MM, Jongeneelen FJ. Effect of the reduction of skin contamination on the internal dose of creosote workers exposed to polycyclic aromatic hydrocarbons. Scand $¥$ Work Environ Health 1993;19:200-7.

5 Van Rooij JGM, Bodelier-Bade MM, Jongeneelen FJ. Estimation of individual dermal and respiratory uptake Estimation of individual dermal and respiratory uptake
of polycyclic aromatic hydrocarbons in 12 coke oven of polycyclic aromatic hydrocarbons in

6 Fenske RA. Dermal exposure assessment techniques. Ann Occup Hyg 1993;37:687-706.

7 Jongeneelen FJ, Scheepers PTJ, Groenendijk A, Van Aerts L, Anzion RBM, Bos RP, et al. Airborne concentrations, skin contamination and urinary metabolite excretion of polycyclic aromatic hydrocarbons among paving workers exposed to coal tar derived road tars. Am Ind Hyg Assoc $\mathcal{F}$ 1988;49:600-7.

8 Van Rooij JGM, Bodelier-Bade MM, De Looff AJA, Dijkmous APG, Jongeneelen FJ. Dermal exposure to polycyclic aromatic hydrocarbons among primary aluminium workers. Med Lav 1992;83:519-29.

9 Goldenhar LM, Schulte PA. Intervention research in occupational health and safety. Occup Med 1994;36: 763-75.

10 Senn S. Cross-over trials in clinical research. Chichester: John Wiley, 1993:1-16.

11 Jongeneelen FJ, Anzion RB, Henderson PT. Determination of hydroxylated metabolites of polycyclic aromatic hydrocarbons in urine. $f$ Chromatogr 1987;413: 227-32.

12 Tolos WP, Shaw PB, Lowry LK, MacKenzie BA, Deng JF, Markel HL. 1-Pyrenol in urine: a biological monitorhydrocarbons. Appl Occup Environ Hyg 1990;5:303-9.

13 Gardiner K, Hale KA, Calvert IA, Rice C, Harrington JM. The suitability of the urinary metabolite 1-hydroxypyrene as an index of polynuclear aromatic bioavailability from workers exposed to carbon black. Ann Occup Hyg from workers exp

14 Jongeneelen FJ, Anzion RBM, Scheepers PTJ, Bos RP, ongeneelen FJ, Anzion RBM, Scheepers PTJ, Bos RP,
Henderson PTh, Nijenhuis EH, et al. 1-Hydroxypyrene in urine as a biological indicator of exposure to polycyclic aromatic hydrocarbons in several work environments. Ann Occup Hyg 1988;32:35-43.

15 Boogard PJ, van Sittert NJ. Exposure to polycyclic aromatic hydrocarbons in petrochemical industries by measurement of urinary 1-hydroxypyrene. Occup Environ Med 1994;51:250-8. 